\title{
PROLONGED IN VIVO EXPOSURE THERAPY WITH A 70-YEAR-OLD WOMAN
}

\author{
BRUCE A. THYER \\ Phobia Clinic, Neuropsychiatric Institute, The University of Michigan
}

\begin{abstract}
Summary-A 70-yr-old woman with a debilitating fear of dogs was successfully treated in five sessions of in vivo exposure therapy, each lasting approximately one hour. This improvement followed $3 \mathrm{yr}$ of unsuccessful verbal psychotherapy and self-administered gradual in vivo desensitization. Treatment gains were maintained at 6 month follow-up.
\end{abstract}

Prolonged in vivo exposure therapy is continuous real life exposure of a phobic person to an anxiety evoking stimulus, and maintaining this exposure until the anxiety is no longer elicited. This technique has been found to be an effective treatment for a variety of anxiety related disorders (Boulougouris and Rabavilas, 1977; Gelder, 1979) and usually relieves the symptomatology of simple phobias in approximately eight sessions (Marks, 1979a). Although the procedure has been extensively investigated in undergraduate volunteers (Mathews, 1978), psychiatric patients (Marks, 1979b) and in children (Kandell, Ayllon and Rosenbaum, 1977; Yule, Sacks and Hersov, 1974), there are no reports in the literature describing its use with elderly patients. The present case study reports on the successful use of in vivo exposure in the treatment of a 70 -yr-old woman with a monosymptomatic phobic disorder.

\section{CASE HISTORY}

The client was a 70 -yr-old widow who was referred to the Phobia Clinic following 3 years of unsuccessful verbal psychotherapy and gradual in vivo desensitization treatment for a severe fear of dogs. The client reported that while on a walk 4 years earlier, she was unexpectedly attacked by a large Saint Bernard dog, whereby she was knocked down from behind and repeatedly bitten upon the head, stomach and buttocks. A passerby pulled the dog off her and took the client for emergency room treatment. Subsequently she experienced stark terror upon seeing or hearing any dog. As time passed she began to curtail her outdoor activities such as walks or shopping, for fear of meeting dogs. Four months after the attack she entered into verbal psychotherapy which did not result in symptom alleviation. During the last ycar of her 3 years of treatment she was instructed to begin a program of selfconducted gradual in vivo desensitization which produced some improvements. However, while on another walk 9 months before her referral to the Phobia Clinic, the client observed a Doberman Pinscher dog approaching her from about 150 yards away. While anxiously attending to the oncoming animal, she slipped on a patch of ice, fell and broke her hip, resulting in a 4 month convalescence and a total relapse of her fear of dogs. At the time of her subsequent referral by her psychotherapist, the client was experiencing severe functional limitations in her daily activities which were beginning to assume agoraphobiclike proportions, as well as ongoing nightmares and insomnia related to her anxiety about dogs.

Requests for reprints should be addressed to Bruce A. Thyer, Phobia Clinic, Room No. 5835, Neuropsychiatric Institute, The University of Michigan, Ann Arbor, Michigan 48109. 
Apart from this one disabling fear the client appeared to lead a satisfying life, was active with friends and outside interests, and had close family ties. She held a doctorate degree and had been retired for 7 years.

\section{TREATMENT}

Since there were no medical contra-indications precluding the use of anxiety eliciting procedures, prolonged in vivo exposure was selected as the treatment method, after the technique was explained to her and her consent obtained. She was told that less discomforting methods were available, should she desire them, such as systematic desensitization or gradual in vivo desensitization, but that in vivo exposure was generally more efficient for the treatment of small animal phobias (Mathews, 1978). She was assured that she would determine the pace of treatment and that she could terminate a session at any time, should she choose to do so.

The first and second sessions used a 10 pound and a 50 pound dog, respectively, as the evoking stimulus. The client was brought into the room where the dog was secured on a leash and then induced through verbal persuasion and support to approach them as closely as possible. As soon as she was comfortable with the dog in close proximity to her and having him lick her hands, she was left alone in the room with the animal for several minutes. She then took the dog outside for a walk, in the presence of the therapist. In both sessions she habituated to the close proximity of the dog within half an hour.

The third session consisted of an hour long visit to the local humane society. Here, following several minutes of exposure to the barking of dozens of dogs simultaneously, the client quickly lost her pronounced startle reflex previously elicited whenever she heard a dog bark. By the time the session was concluded she was calmly reaching into cages, petting a variety of dogs, including a Doberman Pinscher, and letting them lick her.
In the fourth session, the client entered a room where an 80 pound Afghan hound was secured, that was brought as close to her as rapidly as she would permit. After $15 \mathrm{~min}$ she was comfortably feeding the animal dog biscuits and another dog, a 95 pound Great Dane, was announced and brought into the room. At the sight of the larger animal the client became very anxious and burst into tears. After $2 \mathrm{~min}$ she calmed down and gradually allowed the therapist to bring the dog closer and closer. Proceeding as rapidly as the client would permit, the therapist induced her to pet both dogs and to feed them in response to a variety of tricks they performed. She soon became adept at firmly commanding the animals to sit, lie down, play dead, speak, etc., and was able to do this comfortably while the therapist left the room for $5 \mathrm{~min}$. Before the end of the session she was feeding both animals dog biscuits, while the Afghan seated by her feet, and the Great Dane, placed upon the couch along side of her, barked loudly and repeatedly. Throughout the latter portion of this $1 \frac{1}{2} \mathrm{hr}$ session, the client repeatedly exclaimed to the therapist that she couldn't believe that she was actually engaged in the activities she was doing, yet remaining calm.

The fifth session was similar to the fourth, except the Great Dane only was used, and the client did not experience any anxiety at any point.

Between all therapist-conducted exposure sessions the client engaged in a series of behavioral homework tasks consisting of going on walks and visits for gradually longer periods of time in unfamiliar neighborhoods, where it was possible she would unexpectedly encounter free-running dogs, an activity in which she had previously been unable to engage. She reported success in accomplishing these tasks and treatment was terminated at the end of the fifth session, since she was no longer experiencing any phobic symptoms either within the treatment sessions of during her daily routines.

Telephone contacts at 3 months and 6 months 
after termination indicated a maintenance of therapeutic gains and continued satisfaction on the part of the client about her improvements. She was readily able to go out and perform her daily tasks, and the sight and sound of dogs no longer filled her with dread. Ruminations about dogs as well as nightmares of them and related insomnia were also absent throughout the follow-up period.

\section{DISCUSSION}

This case illustrates that prolonged in vivo exposure, the treatment of choice for most instances of simple phobia and obsessivecompulsive disorders (Marks, 1979b; Gelder, 1979), can be safely and effectively utilized with individuals who are substantially older than the usual client seen in outpatient settings. Through the use of in vivo exposure a phobic disorder of 4 years' duration and resistant to more conservative forms of therapy was successfully eliminated in five sessions of approximately $1 \mathrm{hr}$ each. In this instance the anxiety produced by the technique was well tolerated by the client and did not interfere with the course of therapy. Although several of the exposure sessions induced severe anxiety in the client, this was overcome through therapist support and reassurance, and by the passage of time in the presence of the stationary evoking stimulus. The use of well trained animals who would obey commands gave the client the opportunity of experiencing mastery over them, which probably facilitated the anxiety reduction process.

While formal recordings of subjective units of disturbance (SUDS) were not maintained, the client was asked to rate herself periodically on the SUDS scale during treatment, and it was evident within each therapy session that reductions in avoidance behavior were obtained more rapidly than decreases in SUDS. This illustrates the phenomenon of desynchrony between fear and avoidance induced by high demand in vivo treatments as has been previously reported (Rachman and Hodgson, 1974; Hodgson and Rachman, 1974; Grey, Sartory and Rachman, 1979). Extending a treatment session until synchrony is obtained (i.e. concurrent reduction in the self-report of fear and in avoidance behaviors) seems likely to produce greater maintenance and generalization of treatment effects than exposure sessions which use avoidance behaviors as the sole criterion of improvement (Wolpe, 1973).

Acknowledgement-Gratitude is extended to George C. Curtis, M.D., for permission to publish the case material.

\section{REFERENCES}

Boulougouris J. C. and Rabavilas A. D. (Eds.) (1978) The Treatment of Phobic and Obsessive Compulsive Disorders. Pergamon Press, New York.

Gelder M. (1979) Behavior therapy for neurotic disorders. Behav. Mod. 3, 469-495.

Grey S., Sartory G. and Rachman S. (1979) Synchronous and desynchronous changes during fear reduction. Behav. Res. Ther. 12, 319-326.

Hodgson R. and Rachman S. (1974) Desynchrony in measures of fear. Behav. Res. Ther. 12, 319-326.

Kandel H., Ayllon T. and Rosenbaum M. (1977) Flooding or systematic exposure in the treatment of extreme social withdrawal in children. J. Behav. Ther. \& Exp. Psychiat. 8, 75-81.

Mathews A. (1978) Fear-reduction research and clinical phobias. Psychol. Bull. 85, 390-404.

Marks I. (1979a) The cure and care of neurosis. Psychol. Med. 9, 629-660.

Marks I. (1979b) Exposure therapy for phobias and obsessive-compulsive disorders. Hosp. Prac, 14, 101108.

Rachman S. and Hodgson R. (1974) Synchrony and desynchrony in fear and avoidance. Behav. Res. Ther. $12,311-318$.

Wolpe J. (1973) The Practice of Behavior Therapy. Pergamon Press, New York.

Yule W., Sacks B. and Hersov L. (1974) Successful flooding treatment of a noise phobia in an 11-year-old. J. Behav. Ther. \& Exp. Psychiat. 5, 209-211. 